\title{
LUIS CIFUENTES DELATTE. MEMORIAS Y MAGISTERIO
}

\author{
Mariano Pérez Albacete
}

Servicio de Urología. Hospital Universitario Virgen de la Arrixaca. Murcia. España.

\begin{abstract}
Resumen.- OBJETIVO: Con ocasión de celebrarse el centenario del nacimiento del Dr. D. Luis Cifuentes Delatte, y dada su gran personalidad científica, queremos resaltar dos facetas que, entresacadas de sus trabajos y de sus memorias, consideramos que no han sido suficientemente destacadas: su papel de historiador de la Urología tanto por la narración que realiza de sus vivencias como por la exposición histórica de varias patologías y también su labor docente como maestro de varias generaciones de urólogos, con el objetivo de acercarnos a conocer su gran calidad humana puesta de manifiesto a lo largo de toda su vida y recogida en sus escritos.
\end{abstract}

Mariano Pérez Albacete Cra. Murcia-Cartagena, s/n 30120 El Palmar. Murcia. (España). Mariano.perez2@carm.es
MÉTODOS: Repasamos sus libros y sus trabajos, conferencias y artículos varios publicados, además de noticias que sobre él hemos localizado en diversos medios y, tras el análisis, principalmente de sus memorias, extraemos cuantos datos nos reflejan su modo de ser, de pensar y de actuar.

RESULTADO: Desde joven acompañó a su progenitor a los encuentros urológicos internacionales donde trató a gran número de figuras de la Urología mundial, con las que amplió estudios, y con las que, más adelante, mantuvo excelente relación. Recorrió Europa antes de la Segunda Guerra Mundial y Estados Unidos después con estancias en los centros de mayor prestigio, todo lo cual describe con minuciosidad. Nos relata también la actividad mantenida en los dos primeros años de su dirección en el servicio de Urología del Hospital de la Princesa de Madrid y cita la serie de colaboradores que tuvo. Realiza, en sus trabajos de investigación, una amplia descripción del desarrollo histórico como introducción a las variadas patologías que analizó en profundidad.

CONCLUSIÓN: La lectura de la narración de los viajes que efectuó en la convulsa época internacional que le tocó vivir nos ofrece detalles que nos permiten conocer de primera mano la situación de la Urología así como el lado humano de los protagonistas con los que se relacionó y la vida social que mantenían, además de datos sobre su familia y su vida cotidiana. Como investigador de capítulos trascendentales de la patología urológica resalta su evolución histórica. El gran número de discípulos que se benefició de su magisterio es una muestra indeleble de su calidad científica y de su gran preocupación docente.

Palabras clave: Historia de la Urología. Docencia urológica. Luis Cifuentes Delatte. Semblanzas urológicas. 
Summary.- OBIECTIVES: With the celebration of the centenary of the birth of Dr. Luis Cifuentes Delatte, due to his great scientific personality, we want to emphasize two features that, taken from his works and memories, we consider have not been emphasized enough: his role as historian of urology, both for the histories he narrated of his life experiences and the historical exposition of several pathologies, and also his teaching as professor of several generations of urologists, with the objective of trying to get to know his great human quality as he demonstrated over his life and showed in his writings.

METHODS: We review his books and works, lectures and published papers, in addition the news about his person we have collected from the media, and after analysis, mainly of his memories, we extract data reflecting his personality, and they way he thought and behaved.

RESULTS: Since he was young he went with his father to the international urology meetings where he met a great number of personalities in the World of Urology; he extended his training with them, and later on they got to have a great relationship. He travelled around Europe and United States before and after Second World War, respectively, with stays in the most prestigious centers, which he described meticulously. He also reported his activity during the first two years he directed the Department of Urology at the Hospital La Princesa in Madrid and cited the series of collaborators he had. In his research works he made an ample description of historical development as introduction to the various pathologies he analyzed in depth.

CONCLUSIONS: The reading of the narration of his trips, that he did in the convulse International time he lived, offers details which enable us to know firsthand the situation of urology and the human side of the actors he had relation with, and the social life they had, in addition to data about their families and daily life. As a researcher in transcendental chapters in urological pathology we emphasize his historical evolution. A great number of disciples benefited from his scientific quality and his great teaching vocation.

Keywords: History of urology. Teaching in urology. Dr. Luis Cifuentes Delatte. Urological life sketches.

"Ser maestro, ese título altísimo que no se gana en oposiciones ni en concursos y que muy pocos alcanzan"

Luis Cifuentes, en el homenaje a su padre. 1972
Ya casi octogenario (Figura 1) rememora sus andanzas juveniles y nos relata en Mi primer congreso cómo, recién acabada la carrera en la aulas de San Carlos y a punto de comenzar los estudios del doctorado, acompañó a su padre a París, al de la Asociación Francesa de Urología en octubre de 1930 y nos describe la espléndida época del inicio del otoño en la ciudad del Sena, con sus árboles de hojas ya amarillentas y su bullicio, repleta de visitantes. Conoció a Marion en una comida íntima, a la que asistió junto con su progenitor, nos retrata al profesor físicamente, fuerte, de anchas espaldas y con aspecto rudo, de origen campesino, que contrasta con su empaque profesoral y se emociona al estar frente al autor de un magnífico tratado de Urología. Se deshace en elogios de Octave Pasteau, colaborador de Félix Guyon en el Hospital Necker, al que ve como un venerable y activo representante de la pujante urología francesa del XIX, con su apariencia de hombre mayor de luenga barba y pelo cano y su comunicación versó sobre cómo diferenciar por palpación un riñón grande de una esplenomegalia. Señala la viva impresión que le causó la presencia del profesor Alexander von Lichtenberg, creador de la urografía intravenosa, exploración que a partir de aquellas fechas revolucionó el diagnóstico urológico, y con quien, tres años más tarde, realizó, por espacio de seis meses, prácticas en su clínica de Berlín, considerada por entonces como la cima de la urología europea (Figura 2). Todo el ameno artículo se encuentra acompañado del análisis de las persona-

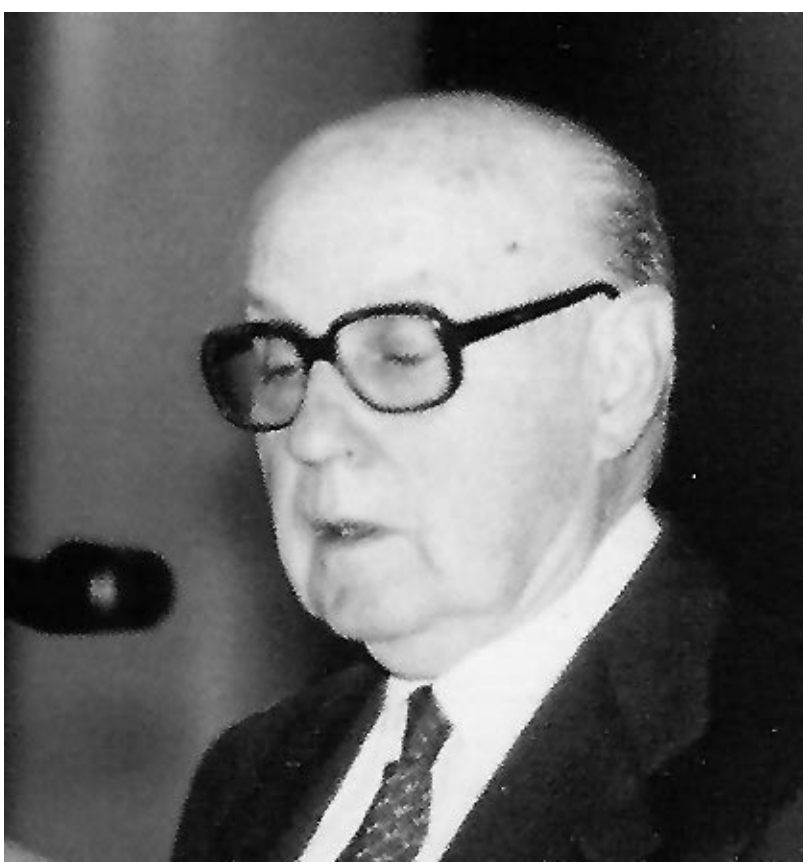

FIGURA 1. Dr. D. Luis Cifuentes Delatte, Madrid, 12.XI. 1907-15.II.20051. 
lidades que trató y de descripciones urológicas, así como de experiencias y anécdotas varias.

Recuerda, también, su asistencia al III congreso Hispano Portugués de Urología y IX de la AEU, celebrado en Coimbra en 1932, detalla la sensación que le produjeron la bella ciudad portuguesa y su universidad, ésta como una de las más destacadas de la península ibérica; habla de los alegres estudiantes vestidos de negro con sus típicas y amplias capas, que, a pesar del calor de julio, lucían, con quienes compartió algunos ratos de jarana y describe varias de sus jocosas costumbres. Alaba al profesor Reynaldo dos Santos, gran patriarca de la Urología del país hermano, quien realizó la primera aortografía y fue un excelente endoscopista y habilidoso reseccionista. Celebra al profesor Stutzin, de Berlín, como la figura más notable de la reunión, cordial, amable y correcto pero de aspecto misterioso, solitario y con una actitud algo desconcertante en aquel momento debida, como supo cuando lo fue a visitar en febrero de 1933, durante su estancia germana, a ser tildado de judío en la Alemania de aquellos años, ya que, aunque descendía de hebreos, era católico.

Junto con Enrique Pérez Castro y Antonio Puigvert fundó en 1944 Archivos Españoles de Urología, publicación decana en la actualidad de nuestra especialidad y en la que, con ocasión de sus cuarenta y cincuenta aniversarios, escribe dos artículos de sabor histórico explicativos de las circunstancias de su creación acompañados de algunas entrañables fotos (Figura 3). También encontramos, entre sus páginas, su contribución al homenaje que la Urología española tributó a Joaquín Albarrán, en 1962, con

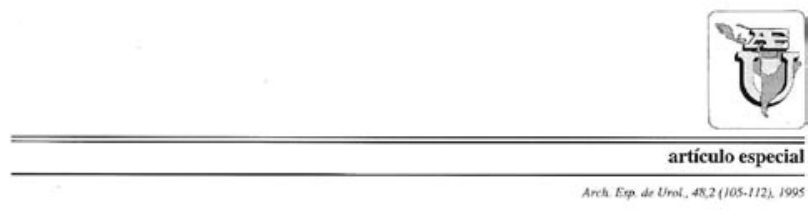

LA CLINICA UROLOGICA DE VON LICHTENBERG EN BERLIN (1933)

L. CIFUENTES DELATTK

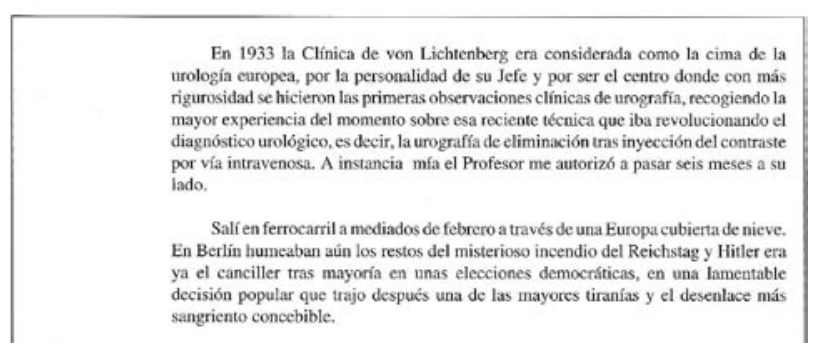

FIGURA 2. La clínica urológica de Von Lichtenberg en Berlín (1933). motivo de cumplirse el centenario de su nacimiento, y años más tarde, 1980, la nota necrológica de Pérez Castro.

En su discurso de ingreso en la Real Academia de Medicina sobre Origen y desarrollo de los cálculos renales (Figura 4), en 1972, se retrotrae hasta la concepción que sobre su formación expone el gran urólogo Francisco Díaz en el siglo XVI y desarrolla después los escritos de cuantos investigadores aportaron una contribución al conocimiento de la producción de la litiasis, de sus clases y de su estructura y en la Historia del estudio microscópico de los cálculos del aparato urinario, en 1981, cuenta el resultado de sus pesquisas sobre los antecedentes, las primeras imágenes y los primeros trabajos acerca de los métodos de estudio de las piedras del riñón.

Nos deleita, en enero de 1974, con la conferencia inaugural del año Académico de la Real de Medicina sobre la Historia de la prostatectomía (Figura 5), que considera como una de las técnicas más atractivas dentro del progreso y evolución que ha llevado la cirugía en los últimos cien años, se explaya en analizar las figuras y las aportaciones de cuantos participaron con su trabajo en su desarrollo hasta alcanzar el perfeccionamiento que la operación ha logrado.

Cuando en 1950 obtuvo por oposición la plaza de jefe del servicio de Urología del Hospital de la Princesa, de Madrid, tras la jubilación de su padre, Pedro Cifuentes, nos presenta el servicio y nos informa de su progresión en los dos primeros años de su jefatura, en los que aumenta el número de camas y en los que consigue la creación de una sala de endoscopia y de un laboratorio urológico, desglosa la patología asistida y las intervenciones quirúrgicas

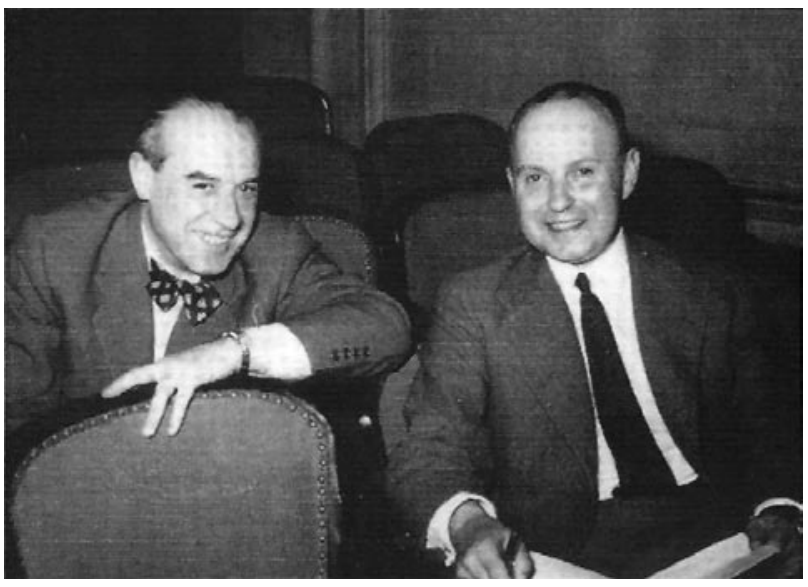

FIGURA 3. Drs. Puigvert y Cifuentes en 1944, creación de Archivos Españoles de Urología. 
INSTITUTO DE ESPAÑA

REAL ACADEMIA NACIONAL DE MEDICINA

\section{ORIGEN Y DESARROLLO}

DE LOS

\section{CALCULOS RENALES}

DISCURSO EN EL ACTO DE RECEPCIÓN DEL

Excmo. SR. DR. D. Luis Cifuentes Delatte

$$
\text { Y CONTESTACIÓN POR EL }
$$

Excmo. SR. Dr. D. Pedro Laín Entralgo

EL DíA 30 DE MAYO DE 1972

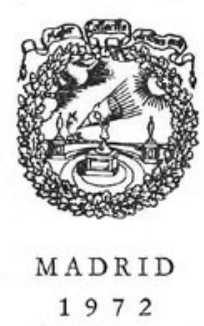

FIGURA 4. Origen y desarrollo de los cálculos renales.

efectuadas, lo que nos permite evaluar la calidad asistencial lograda y conocer la terapéutica ejercida de la que destacamos la resección transuretral tanto de los tumores vesicales como de la próstata, llevada a cabo ya en aquellos años, así como la gran cantidad de nefrectomías realizadas.

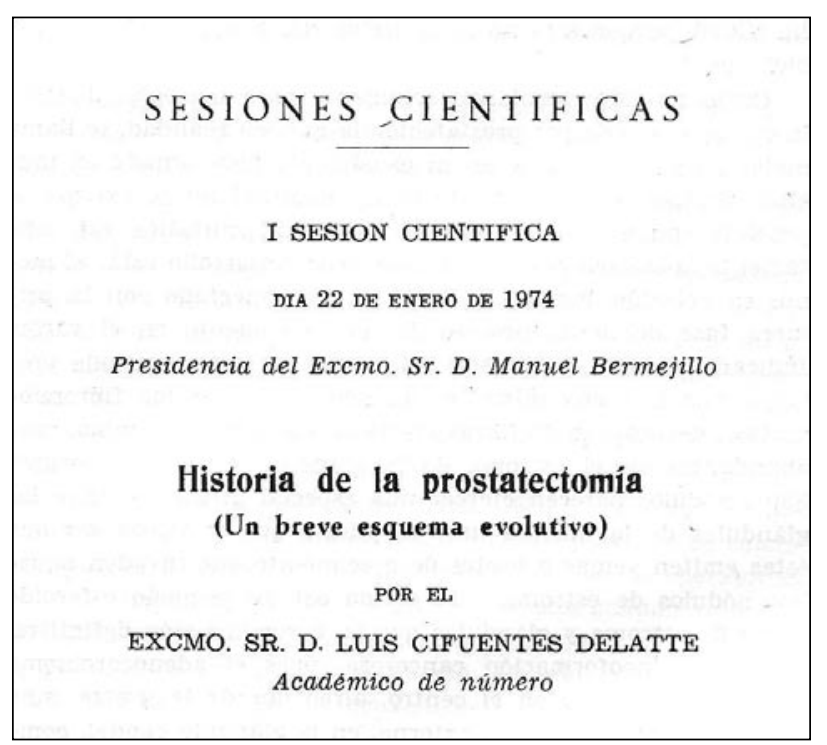

FIGURA 5. Historia de la prostatectomía.
Acudieron, a la sombra de su magisterio, numerosos médicos españoles y bastantes sudamericanos, tanto al Hospital de la Princesa (Gran Hospital de la Beneficencia General del Estado, de 1956 a 1984) entre 1950 y 1970 como al de la Clínica de la Concepción, Fundación Jiménez Díaz, de la que fue consultor de Urología primero y responsable del servicio desde 1970 hasta su retiro en 1986, fue también, profesor de la asignatura en la Universidad Autónoma de Madrid; la reseña, aunque sólo sea de los nombres de los que se formaron en la especialidad a su lado, sería engorrosa y con ausencias, además de rebasar las pretensiones de este trabajo.

Su empeño por enseñar adecuadamente a efectuar una resección transuretral fue uno de sus mayores preocupaciones docentes, nos narra en 1993, en un capítulo de sus memorias (Figura 6), cómo, tras ver operar a Reinaldo Dos Santos en Lisboa, se interesó por el procedimiento y afrontó su aprendizaje en Estados Unidos, con el Dr. Nesbit, del que había leído su libro; en 1946, tras un azaroso viaje, llegó a su clínica en Ann Arbor para enfrascarse en el conocimiento y práctica de la extracción endoscópica de la próstata. Todas las dificultades por las que pasó las reseña, para allanar la instrucción de la generación de urólogos españoles, en su libro de 1961, Cirugía urológica endoscópica, como "consejos personales sobre el método de resección de un adenoma prostático" y en un didáctico y ameno artículo (Figura 7), en el que señala el difícil e ingrato camino que habían de recorrer, antes de la aparición de las ópticas de enseñanza, que quedaba supeditado a poder mirar a través del ocular, si el operador dejaba, y a evaluar la evolución de la resección en fases aisladas; D. Luis, con su gran paciencia, permitía hacerlo el mayor número de veces posible y explicaba la importancia que tiene observar los movimientos de la mano del cirujano, ver su ritmo de trabajo, la posición del cuerpo en las diferentes etapas de la operación, el juego coordinado del pie en el pedal del bisturí y de los dedos al accionar el corte, todo ello

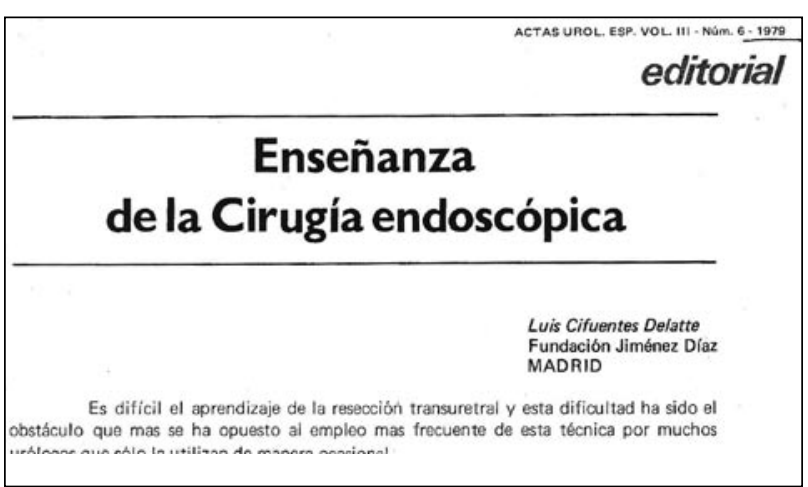

FIGURA 6. Enseñanza de la cirugía endoscópica. 
tan trascendental como lo anterior; al principiante le aconseja ejercitarse ante un fantoma de entrenamiento con una pieza de prostatectomía y resecarla poco a poco, con el fin de acostumbrarse y de lograr seguridad en el manejo del aparato; la percepción de la profundidad del campo y el conocimiento del área endoscópica son puntos que se adquieren con la práctica. Indica que realizar la intervención con una técnica correcta redunda en beneficio del enfermo. De igual modo alecciona sobre el modo de efectuar la resección endovesical de los tumores vesicales.

Finalmente, en el discurso inaugural de la Real Academia de 1976, Comentarios a la evolución de la Urología, repasa su desarrollo en todos sus aspectos, expone la trayectoria histórica que ha llevado desde sus inicios, pormenoriza los eventos de mayor trascendencia que dieron lugar a su constitución, adornado con su análisis personal y acompañado de sus experiencias. Señala que, para mantener la calidad de la Urología como arte y como ciencia, hay que estimular en los jóvenes el entusiasmo por el futuro de la especialidad e incitarles a trabajar con esa finalidad.

En la mayoría de sus relatos aparecen notas y detalles personales de sus apreciaciones y de sus sentimientos expuestos de un modo sincero y amable que enriquecen la acción y que nos permiten entrever su sencillo modo de ser; en ellos se trasluce también su gran formación científica y humana, su entusiasmo por su vocación, por su trabajo y por su papel investigador. Respetuoso con todos sus colaboradores y ayudantes, a quienes identifica y atribuye sus logros ya que, sin su participación, afirma, no se hubiese conseguido culminar con éxito el objetivo propuesto. Desde siempre agradece a "su querido y siempre recordado maestro Dr. Jiménez Díaz su amor por la investigación clínica" que inculcó en él (y del que fue uno de sus más aplicados discípulos). De igual modo reconoce la preparación recibida de su progenitor, de quien heredó su espíritu académico y vehemente dedicación a la misión de ayudar al doliente.

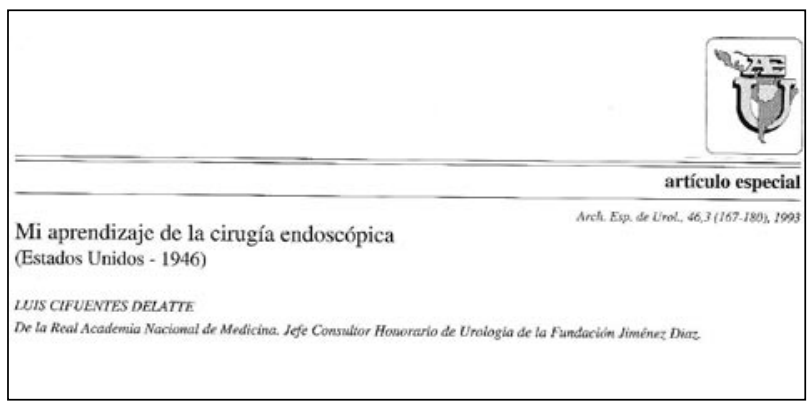

FIGURA 7. Mi aprendizaje en cirugía endoscópica (Estados Unidos, 1946).
Sin ser amigo de distinciones recibió gran número de ellas; si cabe una de las que más estimó fue la concesión de la Medalla Francisco Díaz de la Asociación Española de Urología, en 1976, como gran maestro de la especialidad y en reconocimiento de toda su labor científica, de su consagración y de su entrega a la Urología.

En el terreno científico resalta la ponencia del profesor Ángelo da Fonseca sobre el empleo del "punch de Caulk", en la patología del cuellos vesical, ya que aún no habían llegado a la península los primeros resectoscopios y destaca la del profesor Leonardo de la Peña sobre el reflujo vésico ureteral, que se anticipó veinte años a la plétora de trabajos sobre esta patología y su corrección quirúrgica. En el terreno de las comunicaciones destaca su contribución ya en esas tempranas fechas de sus estudios sobre la bacteriología en el tratamiento de las cistitis.

Narra éste la evolución del servicio desde la creación en 1890 de la consulta de Vías Urinarias, atendida por el Dr. Barragán al que sucedió en 1908 tras su regreso de París donde se especializó en Uro-

INSTITUTO DE ESPAÑA

REAL ACADEMTA NACIONAL DE MEDICINA

PALABRAS SIN IMAGENES

\section{Comentarios a la evolución de la Urología}

Discurso de inauguración del año 1986 Real Academia Nacional de Medicina POR EL

EXCMO. SR. D. LUIS CIFUENTES DELATTE Académico de número

DISCURSO

leído en la solemne sesión inaugural del curso 1986 , celebrada el día 14 de enero de 1986

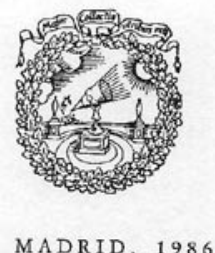

FIGURA 8. Comentarios a la Evolución de la Urología. 
logía, fue ascendido a jefe de sala de Cirugía General en 1910, comenzó a incrementar los ingresos de pacientes urológicos, labor constante que condujo a que ya en 1918 todos los enfermos eran de Urología, lo que la dirección del centro aceptó como hecho consumado y algo después una orden ministerial la reconocía oficialmente con la creación del servicio de Urología.

Su labor investigadora comienza con el estudio de las cistitis, que define como "uno de los capítulos más incompletos y peor conocidos de nuestra especialidad", constituyó su primer reto al poco de finalizar su educación urológica en 1932, con el artículo Contribución al estudio de las cistitis y que culmina con el excelente libro, Cistitis y cistopatías en 1948, en el que aborda todas las causas inflamatorias y degenerativas que las producen y de las que, en el prólogo de su segunda edición, en 1961, afirma "que no ha surgido en la bibliografía universal ninguna nueva obra que fuese dedicada concreta y especialmente a este problema" lo que no da una idea de la amplitud de su trabajo, de lo difícil del conocimiento de esta patología así como de la ardua labor de estudio que requirió su gestación primera, así como el esfuerzo de presentarlo completamente renovado y reestructurado, trece años después, lo que le supuso revisar toda la bibliografía última aparecida sobre el tema.

El segundo estudio lo protagoniza el origen y desarrollo de los cálculos renales iniciado en los años 50, al poco de comenzar su labor en el Hospital de la Princesa, con el análisis de la cristaluria y de la litiasis de ácido úrico, lo que le condujo a lograr su disolución con un tratamiento alcalinizante acompañado de la ingestión de ácido cítrico, prosiguió con la investigación del metabolismo fosfo-cálcico y del ácido oxálico, por medio de la espectrografía de infrarrojos, más adelante, de los cortes finos de cálculos observados con luz polarizada y, por último, el análisis de los núcleos litiásicos con microscopía electrónica de barrido. Con el descubrimiento del corynebacterium urealítico, como agente productor de los cálculos infecciosos, culmina sus treinta años de trabajo en este campo que queda recogido en 1984 en su obra Composición y estructura de los cálculos renales.

El conocimiento de la patología tumoral vesical le atrae desde los inicios de la exploración endoscópica y de la citología urinaria, clasifica el tumor y le preocupa su evolución con un estudio estadístico sobre 1000 casos.

La evolución de la vejiga neurógena es otro de los temas en los que centra su investigación para ampliar su conocimiento.
En las 156 páginas de su interesante libro, El laboratorio de urólogo nos ofrece, en 1974, una lección magistral en la que imbrica al especialista en el análisis rutinario del sedimento de orina en fresco, como inestimable ayuda para un diagnóstico inmediato, económico, sencillo de realizar y útil, en el que señala paso a paso cuantos componentes se pueden encontrar con la orina junto con su valoración clínica.

\section{BIBLIOGRAFIA y LECTURAS RECOMENDADAS ( ${ }^{*}$ lectura de interés $y^{* *}$ lectura fundamental)}

*1. El Dr. Luis Cifuentes Delatte, jefe del servicio de Urología del Hospital de La Princesa de Madrid. Arch. Esp. Uro. 1950; VI (2): 206-207.

*2. Informe del servicio de Urología del Hospital de La Princesa de Madrid. Arch. Esp. Uro. 1952; VIII (1): 78-89.

3. Técnica de la resección endoscópica de los papilomas vesicales. Arch. Esp. Uro. 1956; XII (4): 215-230.

**4. Cirugía endoscópica: fundamentos indicaciones y técnica. 1961; edt. Paz Montalbo, Madrid. $2^{\text {a }}$ edic. 1980; Paz Montalvo, Madrid.

5. Homenaje al profesor J. Albarrán. Arch. Esp. Uro. 1962; XV (3): 206-265.

Origen y desarrollo de los cálculos renales. Discurso de ingreso, 1972; Real Acad. Nacional Medicina, Madrid.

6. Historia de la prostatectomía. Un breve esquema evolutivo. 1974; An. R. Acad. Med. XCI: 3.

*7. Enseñanza de la cirugía endoscópica. Actas Urol. Esp. 1979; III (6): 303-306.

8. Enrique Pérez Castro (1908-1980) (necrológica): Arch. Esp. Uro. 1980; XXXIII (6): 523.

9. Historia del estudio microscópico de los cálculos. Arch. Esp. Uro. 1981; XXXIV (5): 375-385.

10. 40 Aniversario de Archivos Españoles de Urología. Arch. Esp. Uro. 1984; XXXVII (1):1-5.

*11. Mi primer Congreso. Actas Urol. Esp. 1985; núm. extra: 9-12.

*12. Palabras sin imágenes. Comentarios a la evolución de la Urología, 1986; Real Acad. Nacional Medicina, Madrid.

*13. Mi aprendizaje de la cirugía endoscópica (Estados Unidos, 1946). Arch. Esp. Uro. 1993; XLVI (3): 167.

14. El 50 aniversario. Arch. Esp. Uro. 1994; XLVII (6): 548-553.

*15. La clínica urológica de von Lichtenberg en Berlín (1933). Arch. Esp. Uro. 1995; XLVIII (2): 105117. 